[Technical Paper]

\title{
UV Laser Releasable Temporary Bonding Materials for FO-WLP
}

Hikaru Mizuno, Hiroyuki Ishii, Hitoshi Kato, Takashi Mori, Hiroki Ishikawa, Yooichiroh Maruyama, Kenzo Ohkita, and Koichi Hasegawa

Advanced Electronic Materials Laboratory, Fine Electronic Materials Research Laboratories, JSR Corporation 100 Kawajiri-cho, Yokkaichi, Mie 5108552, Japan

(Received August 16, 2018; accepted November 22, 2018, published December 25, 2018)

\begin{abstract}
Temporary bonding/de-bonding (TBDB) technology in a FOWLP process is required to adapt to a low temperature process because of the potential for damage in handling the thin molded compound embedding dies. We have developed laser releasable TBDB materials for low temperature bonding processes that enable UV laser release with high throughput and low thermal/mechanical stress. The developed TBDB materials consist of two layers, an adhesive layer and a release layer. The appropriate wafer bonding temperature can be controlled by the molecular weight of the polymer which is the main component of the adhesive material. Good bonding property has been seen, even at $160^{\circ} \mathrm{C}$ by adopting the lowest molecular weight polymer. On the other hand, the release layer material exhibits excellent stability that allows for fabrication of RDLs directly onto the layer to give a stacked structure in the Chip-last (RDL-first) method. The laser energies preferred for wafer release processes are $130 \mathrm{~mJ} / \mathrm{cm}^{2}$ for a $308 \mathrm{~nm}$ excimer laser and $190 \mathrm{~mJ} / \mathrm{cm}^{2}$ for a $355 \mathrm{~nm}$ YAG. These materials will be promising for advancements of FO-WLP applications.
\end{abstract}

Keywords: Temporary Bonding, Laser de-bonding, FO-WLP, 3D Packaging, Laser Ablation

\section{Introduction}

In recent years, novel electronic products have become dramatically smaller and more highly functionalized. At the same time, the amount of information to be processed through semiconductor devices has increased at an accelerated pace. In order to handle huge amounts of data at high speed, small size and with low energy consumption, advanced electronic packages such as Fan-Out Wafer Level Package (FO-WLP), 2.5D interposer and 3D-TSV have been developed.

FO-WLP allows for enhanced I/O interconnections by extending the package size, through the re-distribution layer (RDL), beyond the area of the chip relative to conventional Fan-In Wafer Level Package (FI-WLP) which has a limited I/O count. Moreover, FO-WLP has the advantage of extensibility for mounting of multiple chips on a package for high performance as in functional integration process of Fan-Out System-in Package (FO-SiP). To fabricate these highly integrated devices, temporary bonding/debonding (TBDB) technology is necessary.

The representative FO-WLP process includes build-up $\mathrm{RDL}$, epoxy molding compound (EMC), and dies on the carrier wafer (Fig. 1). Thus, it is sometimes necessary to

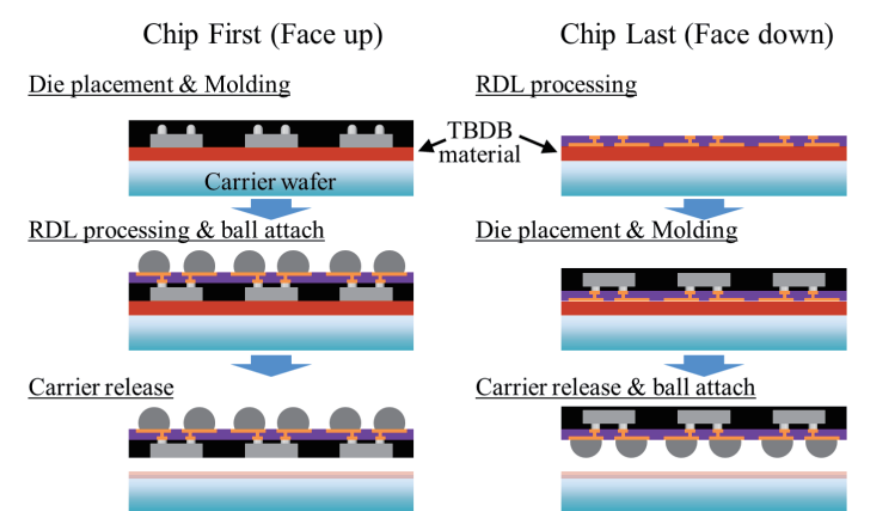

Fig. 1 TBDB material in FO-WLP process.

limit the process temperature to less than $200^{\circ} \mathrm{C}$ to prevent warpage, outgassing of the EMC wafer or solder damage. Therefore, TBDB materials must adapt to low temperature processes. Also, the TBDB materials must remain stable in the process conditions through lithography, electroplating in the RDL and mold fabrication. [1-7]

In this paper, laser releasable TBDB materials adaptable to a low temperature bonding process, and the release material with high durability through the FO-WLP process, is described. 
Table 1 Comparison of laser wavelength.

\begin{tabular}{|c|c|c|c|c|}
\hline \multirow{2}{*}{ Item } & \multicolumn{4}{|c|}{ Laser wavelength } \\
\hline & $308 \mathrm{~nm}$ & $355 \mathrm{~nm}$ & $532 \mathrm{~nm}$ & $1,064 \mathrm{~nm}$ \\
\hline Mechanism & $\begin{array}{l}\text { Photonic } \\
\text { cleavage }\end{array}$ & $\begin{array}{l}\text { Photonic } \\
\text { cleavage }\end{array}$ & $\begin{array}{c}\text { Thermal or } \\
\text { Photonic }\end{array}$ & $\begin{array}{c}\text { Thermal } \\
\text { degradation }\end{array}$ \\
\hline $\begin{array}{c}\text { Thermal } \\
\text { effect }\end{array}$ & $\begin{array}{c}\text { Low } \\
\text { damage }\end{array}$ & $\begin{array}{c}\text { Low } \\
\text { damage }\end{array}$ & Intermediate & $\begin{array}{l}\text { High } \\
\text { thermal } \\
\text { damage }\end{array}$ \\
\hline $\begin{array}{l}\text { Equipment } \\
\text { cost }\end{array}$ & $\begin{array}{c}\text { Intermediate } \\
\text { (excimer) }\end{array}$ & $\begin{array}{c}\text { Low } \\
\text { (solid state) }\end{array}$ & $\begin{array}{c}\text { Low } \\
\text { (solid state) }\end{array}$ & $\begin{array}{c}\text { Low } \\
\text { (solid state) }\end{array}$ \\
\hline
\end{tabular}

\section{Technical Approach}

\subsection{Laser release technology}

As of today, four kinds of TBDB systems received the most attention: thermal slide, mechanical release, solvent release and laser release. The laser release system has an advantage because of its low de-bonding temperature, low mechanical stress, and high throughput characteristics. [8-11] In addition, the broad process window of the laser release system is better for the FO-WLP application compared with the other conventional de-bonding systems.

The representative laser release wavelength and its features are shown in Table 1. The differences are addressed in terms of the laser-induced ablation reaction mechanism, thermal effect and de-bonding equipment cost. In this study, we focused on UV laser release systems with $308 \mathrm{~nm}$ and $355 \mathrm{~nm}$ in wavelengths because they satisfy the trend to decrease operation temperature to minimize the potential for thermal damage to a package.[12-14]

\subsection{Concept of TBDB material for laser release sys- tem}

Two kinds of representative FO-WLP fabrication processes are shown in Fig. 1. One is the chip-first approach which includes die placement, molding and solder ball attachment. The other is the chip-last approach. In this scheme, RDLs are built-up onto the TBDB material directly. A lower process temperature is preferred to prevent wafer warpage, outgassing from EMC, and solder damage. Moreover, durability against various chemicals such as solvents and etchants are required. After the die embedded wafer is fabricated by these procedures, further processing to the opposite side of the device can be with by a second TBDB process.

The TBDB materials we have developed consist of an adhesive layer and a release layer as shown Fig. 2. The adhesive layer, which provides high adhesion, is located on the device wafer side, and the release layer is located between the adhesive layer and glass carrier wafer. The

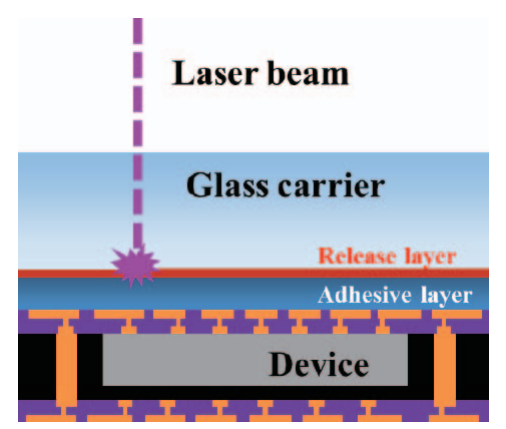

Fig. 2 Layout example of TBDB materials.

adhesive material is designed based on aromatic polymers which have hydroxyl groups that provide enough adhesion strength between the bonded wafer pair and allow easy removal during a wet cleaning process after laser releasing. We investigated polymer structures to satisfy low temperature bonding. On the other hand, the release material is also designed based on a thermosetting aromatic main polymer which incorporates functional groups that show high ultraviolet absorption for the cleavage of molecules in a photo-chemical manner.

\section{Experimental Section}

\subsection{Properties of adhesive materials}

Glass transition temperature ( $\mathrm{Tg}$ ) of the adhesive materials were measured by a Thermo-Mechanical Analyzer (TMA). Mechanical properties (tensile strength, elongation, and elastic modulus) were evaluated with a $20 \mu \mathrm{m}$ thick specimen by a Shimadzu tensile testing machine AGS-500NX. Thermal stability of the materials was evaluated with the temperature of $1 \%$ weight loss determined by thermogravimetric analysis (TGA). Shear viscosity of adhesive materials were measured by Rheometer AR-G2 (TA Instruments) with specimens which were molded to $1.0 \mathrm{~mm}$ thick after solvent removal.

\subsection{Wafer bonding}

Wafer bonding was conducted by a thermo-compressive procedure under vacuum. First, a $500 \mathrm{~nm}$ thick release 
Table 2 Film properties of adhesive material.

\begin{tabular}{c|c|c|c}
\hline \multirow{2}{*}{ Item } & \multicolumn{3}{|c}{ Adhesive material } \\
\cline { 2 - 4 } & Adhesive-A1 & Adhesive-A2 & Adhesive-A3 \\
\hline $\begin{array}{c}\text { Molecular weight of main polymer } \\
\text { (relative ratio) }\end{array}$ & 1.00 & 0.82 & 0.43 \\
\hline Glass transition temperature & $90^{\circ} \mathrm{C}$ & $90^{\circ} \mathrm{C}$ & $89^{\circ} \mathrm{C}$ \\
\hline Tensile strength & $56 \mathrm{MPa}$ & $50 \mathrm{MPa}$ & $52 \mathrm{MPa}$ \\
\hline Elongation & $150 \%$ & $100 \%$ & $50 \%$ \\
\hline Elastic modulus & $1.1 \mathrm{GPa}$ & $1.1 \mathrm{GPa}$ & $1.2 \mathrm{GPa}$ \\
\hline Thermal decomposition temperature & $>350^{\circ} \mathrm{C}$ & $>350^{\circ} \mathrm{C}$ & $>350^{\circ} \mathrm{C}$ \\
\hline
\end{tabular}

a. By Gel permeation chromatography (GPC)

material was spin coated onto a $200 \mathrm{~mm}$ glass carrier wafer. An adhesive material was then coated on top of the release material layer with a thickness of $50 \mu \mathrm{m} \sim 80 \mu \mathrm{m}$ and baked at $110^{\circ} \mathrm{C}$ for 5 minutes, followed by $200^{\circ} \mathrm{C}$ for 10 minutes on a hot plate. Next, a $200 \mathrm{~mm} \mathrm{EMC} \mathrm{wafer} \mathrm{and}$ the glass carrier wafer coated with TBDB materials were bonded at various target temperatures under vacuum by wafer bonder EVG 520 (EV Group). The bonding force was $0.2 \mathrm{MPa}$. After bonding, the bonded pair was inspected for any voids or delamination. Also, a 200 or $300 \mathrm{~mm}$ bonded pair of glass carrier wafer and silicon wafer was prepared by the same procedure to provide for thermal stress test of adhesive.

\subsection{Laser release test}

Laser release was performed on the above mentioned $200 \mathrm{~mm}$ bonded pairs consisting of a glass support wafer coated with TBDB materials and an EMC wafer. Two UV laser sources were applied to the release. One was a third harmonic wave of Nd-doped YAG, which emits a $355 \mathrm{~nm}$ light with $50 \mathrm{kHz}$ oscillation frequency, $200 \mu$ m irradiation spot diameter. The other was a $\mathrm{XeCl}$ excimer laser operated at $308 \mathrm{~nm}$ irradiation with $50 \mathrm{~Hz}$ oscillation frequency, $12.5 \times 4 \mathrm{~mm}$ rectangular beam by ELD300 debond module (SUSS Microtec). The wafer release was carried out by laser irradiation by scanning across the entire $300 \mathrm{~mm}$ wafers. The irradiation pitch can be appropriately adjusted to not produce any un-irradiated areas.

\section{Results and Discussion}

\subsection{Film properties of adhesive layer}

Shear viscosity of the adhesive material is an important factor for bonding. We checked the shear viscosity and mechanical properties of the adhesive materials with different molecular weights of the polymers (Table 2). Figure 3 shows the shear viscosity of the adhesive materials at

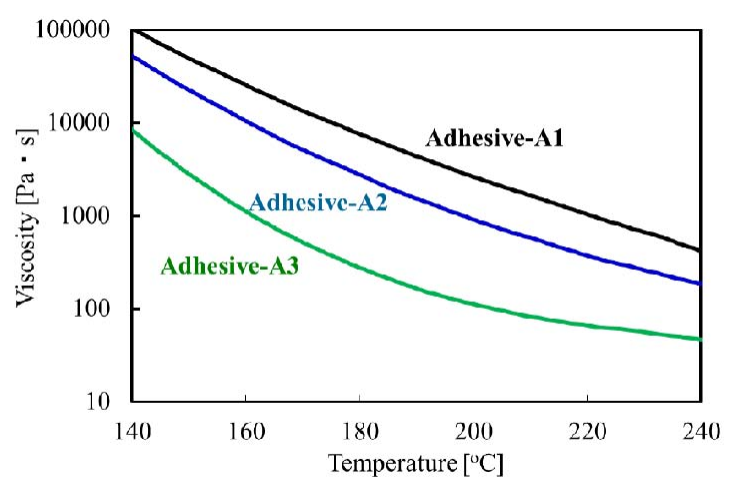

Fig. 3 Shear viscosity curve of adhesive materials.

different temperatures. The viscosity was easily controlled by changing the molecular weight of the main polymer contained in the adhesive material. In this study, we investigated three materials with different shear viscosities; 2,600 Pa.s, $910 \mathrm{~Pa} \cdot \mathrm{s}$, and $110 \mathrm{~Pa} \cdot \mathrm{s}$ at $200^{\circ} \mathrm{C}$ for AdhesiveA1, Adhesive-A2, and Adhesive-A3 respectively.

Table 2 shows the film properties of the adhesive materials. The mechanical properties of Adhesive-A1 and Adhesive-A2 were almost the same except for a slight difference in elongation. Both materials showed good thermal stability. Adhesive-A3 also showed substantially the same glass transition temperature to Adhesive-A1 and A2 despite its lower molecular weight. The mechanical strength of Adhesive-A3 is lower than the others, but it will be enough for holding a bonded pair during processes. Thereby, it is expected to be acceptable as a low temperature bonding material for the TBDB process.

\subsection{Wafer bonding results}

Thermo-compressive bonding of the EMC wafer onto a TBDB coated glass carrier was conducted and the results are summarized in Fig. 4 and Table 3. Adhesive-A1 yielded good bonded pairs without remarkable voids or defects at $220^{\circ} \mathrm{C}$ or higher. On the other hand, some voids could be seen after bonding at $200^{\circ} \mathrm{C}$. In the case of Adheseve-A2, 


\section{Bonding}

Glass carrier coated with TBDB materials

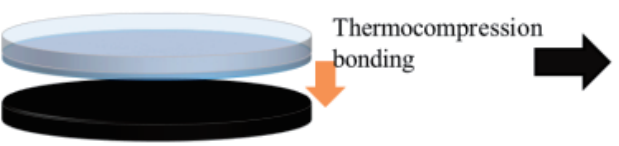

EMC

Fig. 4 Bonding procedure.

Table 3 Bonding test results.

\begin{tabular}{|c|c|c|c|c|c|c|}
\hline \multirow{2}{*}{ Bonding result ${ }^{b, c}$} & \multicolumn{6}{|c|}{ Bonding temperature $\left[{ }^{\circ} \mathrm{C}\right]$} \\
\hline & 140 & 160 & 180 & 200 & 220 & 240 \\
\hline Adhesive-A1 & & Error & & & & \\
\hline Adhesive-A2 & $\mathrm{Er}$ & & & Pas & & \\
\hline Adhesive-A3 & Error & & & Ca & & \\
\hline
\end{tabular}

b. Red arrow: Error (void or delamination exist)

c. Blue arrow: Pass (no void and no delamination)

Table 4 Bonded pairs of EMC and glass carrier wafer with Adhesive-A3.

\begin{tabular}{|c|c|c|}
\hline Bonding temperature & $140^{\circ} \mathrm{C}$ & $160^{\circ} \mathrm{C}$ \\
\hline \multirow[t]{2}{*}{ Observations } & & \\
\hline & $\begin{array}{c}\text { minor void } \\
\text { No delamination }\end{array}$ & $\begin{array}{c}\text { No void } \\
\text { No delamination }\end{array}$ \\
\hline Bonding temperature & $180^{\circ} \mathrm{C}$ & $200^{\circ} \mathrm{C}$ \\
\hline \multirow[t]{2}{*}{ Observations } & & \\
\hline & $\begin{array}{c}\text { No void } \\
\text { No delamination }\end{array}$ & $\begin{array}{c}\text { No void } \\
\text { No delamination }\end{array}$ \\
\hline
\end{tabular}

the threshold for the bonding temperature shifted to $180^{\circ} \mathrm{C}$. Furthermore, Adhesive-A3 yielded good bonded pairs at $160^{\circ} \mathrm{C}$ (Table 4$)$. From these results, reducing molecular weight of the polymer is one of the effective way to get good bonding pair of wafers. The threshold for shear viscosity to obtain good bonding pairs between EMC and the glass carrier wafer should be roughly equal or less than 1,000 Pa.s.

We also conducted thermal stress test of a bonded pair consist of a silicon wafer and a glass carrier wafer bonded with Adhesive-A3. Adhesive-A3 yielded good bonded pairs

\section{Observation}

(6) 
Table 5 Thermal stress test results of bond pairs of $200 \mathrm{~mm}$ silicon wafer and glass carrier bonded with Adhesive-A3.

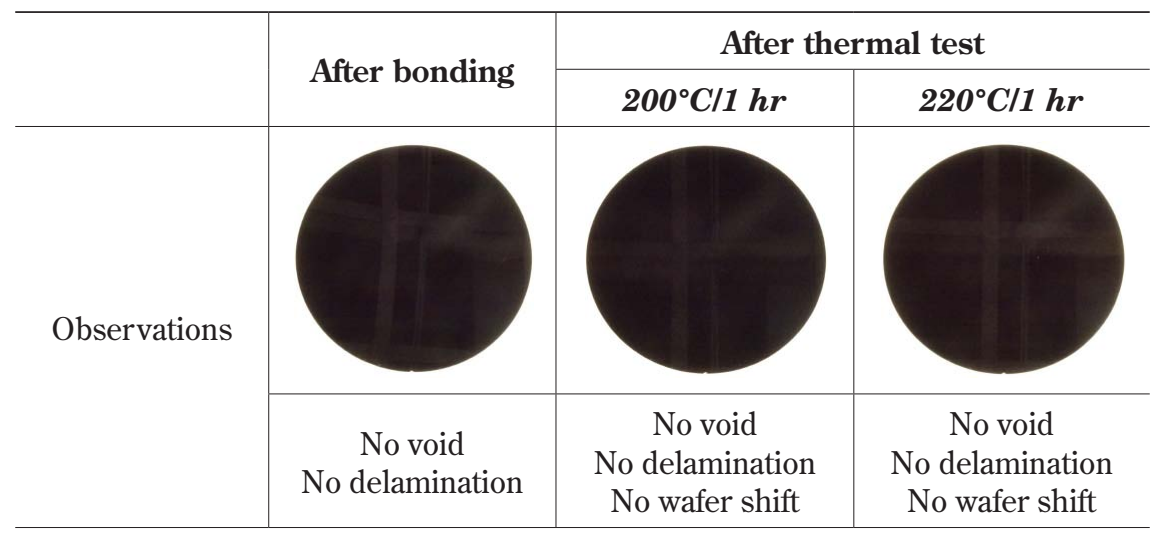

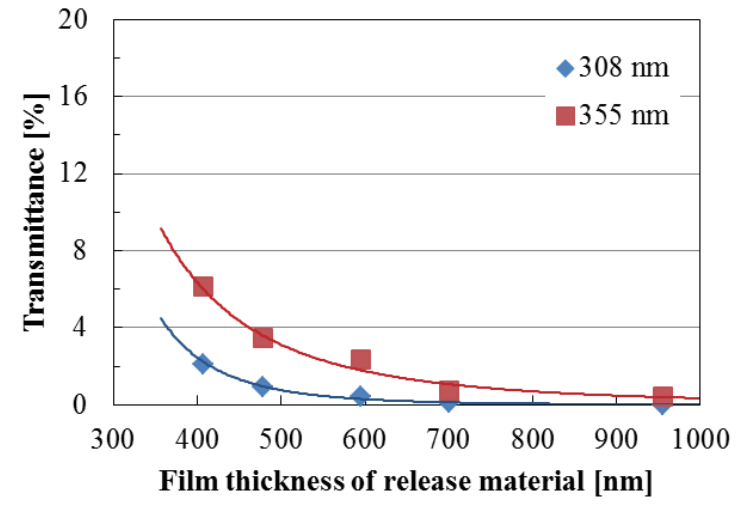

Fig. 5 Transmittance data of release material at $308 \mathrm{~nm}$ and $355 \mathrm{~nm}$ wavelengths.

layer to create a stacked structure in the Chip-last (RDLfirst) method.

To get high laser absorption with a thin film thickness, we designed a thermoset polymer with chromophore units in the molecule. Figure 5 shows transmittance data of the release layer material we developed with different film thicknesses. The transmittances of both materials at 308 $\mathrm{nm}$ and $355 \mathrm{~nm}$ wavelengths are quite low. Specifically, 308 nm light was absorbed more effectively showing $<1 \%$ transmittance at $500 \mathrm{~nm}$ film thickness.

Chemical resistance of the release material was investigated. The release material films coated and cured on glass wafers were dipped into various process solvents such as organic solvents, photo-resist stripper, acid and alkaline. Thus, the process solvents came into direct contact with the release material. The films were then rinsed with DI water and dried. Changes in the film thickness caused by swelling or dissolution were determined by calculation of the film thickness ratio before and after the procedure. Cracking, swelling, wrinkling and discoloration were also checked visually. The results are summarized in Table 6. The release material exhibited excellent chemical
Table 6 Chemical stability of release material.

\begin{tabular}{c|c|c}
\hline Chemicals & Condition & Result $^{\mathbf{d}}$ \\
\hline Acetone & $25^{\circ} \mathrm{C} / 10 \mathrm{~min}$ & Pass \\
\hline PGME & $25^{\circ} \mathrm{C} / 10 \mathrm{~min}$ & Pass \\
\hline PGMEA & $25^{\circ} \mathrm{C} / 10 \mathrm{~min}$ & Pass \\
\hline IPA & $25^{\circ} \mathrm{C} / 10 \mathrm{~min}$ & Pass \\
\hline PR stripper & $60^{\circ} \mathrm{C} / 30 \mathrm{~min}$ & Pass \\
\hline Hydrogen peroxide aq. (30\%) & $50^{\circ} \mathrm{C} / 10 \mathrm{~min}$ & Pass \\
\hline Sulfuric acid aq. (10\%) & $25^{\circ} \mathrm{C} / 30 \mathrm{~min}$ & Pass \\
\hline TMAH aq. (2.38\%) & $25^{\circ} \mathrm{C} / 10 \mathrm{~min}$ & Pass \\
\hline
\end{tabular}

d. Pass: film thickness change is within $\pm 10 \%$ and no appearance change

resistance against the various process chemicals.

Laser releasing performance was examined by using a bonded pair consisting of a glass carrier wafer coated with release material and a bare silicon wafer coated with adhesive material (Adhesive-A1). As a UV laser source, $355 \mathrm{~nm}$ light by YAG solid state laser and $308 \mathrm{~nm}$ by $\mathrm{XeCl}$ excimer laser were used. Optical micrographs of the glass and silicon surface after laser irradiation are summarized in Table 7. Laser marks observed in these micrographs are the areas where the release layer color was changed due to degradation caused by laser irradiation. The material decomposed at less than $200 \mathrm{~mJ} / \mathrm{cm}^{2}$ using both laser light sources and the bonded pair was successfully released. The processing time to release the bonded pair was 60 seconds for $308 \mathrm{~nm}$ laser system and within 90 seconds for $355 \mathrm{~nm}$ system. Therefore, high throughput releasing can be expected due to its high sensitivity to inducing the ablation reaction.

The release performance is thought to depend to a large extent on the properties of release layer. EMC bonded to glass with Adhesive-A1 and release layer material was also 
Table 7 Laser release result of $300 \mathrm{~mm}$ bonded pairs of silicon and glass carrier.

\begin{tabular}{l|c|c|c}
\hline $\begin{array}{c}\text { Laser } \\
\text { wavelength }\end{array}$ & $\begin{array}{c}\text { Irradiated } \\
\text { condition }\end{array}$ & $\begin{array}{c}\text { Laser } \\
\text { release }\end{array}$ & $\begin{array}{c}\text { Optical micrograph } \\
\text { through the glass carrier }\end{array}$ \\
\hline $308 \mathrm{~nm}$ & $130 \mathrm{~mJ} / \mathrm{cm}^{2}$ & $\mathrm{OK}$ & \\
\hline $355 \mathrm{~nm}$ & $190 \mathrm{~mJ} / \mathrm{cm}^{2}$ & OK & \\
\hline
\end{tabular}

released successfully by irradiation of $355 \mathrm{~nm}$ UV laser in the same manner.

The residues of TBDB materials after laser releasing should be easily cleaned from both de-bonded surfaces. In our material design, the residue on the device wafer side composed of silicon and EMC is removed by wet chemicals, while on the glass support wafer side, it is removed by plasma cleaning. The both bonded surface of silicon and EMC after laser releasing were cleaned by wet chemical and the residues were confirmed to be removed completely.

\section{Summary and Conclusion}

Regarding adhesive layer materials, bonding properties can be controlled by changing the molecular weight of the polymer. In this study, Adhesive-A3 yielded good bonded pairs of EMC and a glass carrier at $160^{\circ} \mathrm{C}$. On the other hand, the release layer material was designed to have very high absorption of UV laser light, specifically $308 \mathrm{~nm}$ or $355 \mathrm{~nm}$ in wavelength. As a result, the release layer material contributes to reducing the laser irradiation energy, reducing device damage, and shortening release process time. The bonded pair with the release material was released at less than $200 \mathrm{~mJ} / \mathrm{cm}^{2}$. Also cleaning of the temporary bonding materials both on silicon and EMC were cleaned completely by wet chemicals. Furthermore, it exhibited good stability for fabrication of RDLs directly onto the layer to give a stacked structure in the Chip-last (RDL-first) method. These results show sufficient compatibility to the TBDB process in FO-WLP technology.

\section{References}

[1] G. J. Jung, "Structure and Process Development of
Wafer Level Embedded SiP (System in package) for Mobile Applications,” 2009 11th EPTC, p. 191.

[2] Y. Kurita, "A 3D Stacked Memory Integrated on a Logic Device Using SMAFTI Technology,” 2007 ECTC, p. 821.

[3] S. Yoon, et al., "Mechanical Characterization of Next Generation eWLB (embedded Wafer Level BGA) Packaging,” ECTC, pp. 441-446, 2011.

[4] M. Santarini, "Stacked and Loaded: Xilinx SSI, 28-Gbps I/O Yield Amazing FPGAs,” Xcell Journal, No. 74, pp. 8-13, 2011.

[5] M. Murugesan, et al., "Wafer Thinning, Bonding, and Interconnects Induced Local Strain/Stress in 3D-LSIs with Fine-Pitch High-Density Microbumps and Through-Si Vias,” IEDM, pp. 2.3.1-2.3.4, December 2010 .

[6] M. Tsai, A. Lan, C. L. Shih, T. Huang, R. Chiu, S. L. Chung, J. Y. Chen, F. Chu, C. K. Chang, S. M. Yang, D. Chen, and N. Kao (Siliconware Precision Industries Co., Ltd., SPIL), “Alternative 3D Small Form Factor Methodology of System in Package for IoT and Wearable Devices Application," in Proc. 67th Electronic Components and Technol. Conf. (ECTC), 2017, pp.1541-1546.

[7] J. H. Lau (ASM Pacific Technolgies Ltd.), "Semiconductors and Packaging for the Internet of Things," Chip Scale Review Magazine: Edition May-Jun, 2015, pp. 25-29.

[8] A. Kubo, et al., "Development of New Concept Thermoplastic Temporary Adhesive for 3D-IC Integration,” in Proc. IEEE Electronic Components and Technol. Conf. (ECTC), Lake Buena Vista, FL, May 27-30, 2014, pp. 899-905. 
[9] R. S. E. John, et al., "Low cost, Room Temperature Debondable Spin on Temporary Bonding Solution: A Key Enabler for 2.5D/3D IC Packaging," in Dow Corning Form, No. 11-3388-01.

[10] P. Andry, et al., "Advanced Wafer Bonding and Laser Debonding," in Proc. IEEE Electronic Components and Technol. Conf. (ECTC), Lake Buena Vista, FL, May 27-30, 2014, pp. 883-887.

[11] A. Jourdain, et al., "Temporary Bonding for Hightopography Applications: Spin-on Material Versus Dry Film,” in Proc. IEEE Electronic Components and Technol. Conf. (ECTC), Lake Buena Vista, FL, May 27-30, 2014, pp. 894-898.
[12] H. Hasegawa, et al., "Laser Releasable Temporary Bond/De-bond Materials For Next 3D Packages," in Proc. SMTA Pan Pacific Microelectronics Symposium, 2017.

[13] K. Ito, et al., "Photoablating Characteristics of Various Polymers Irradiated by several Short-Pulse Lasers,” Kobunshi Ronbunshu, Vol. 48, No. 11, pp. 725-735, 1991

[14] Q. Du, et al., "Surface microstructure and chemistry of polyimide by single pulse ablation of picosecond laser,” Applied Surface Science, Vol. 434, pp. 588$595,2018$.

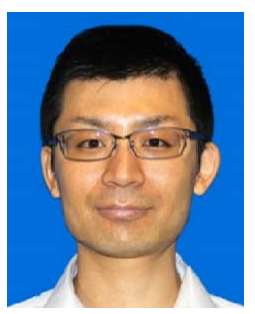

Hikaru Mizuno received the M.Sc. Degree from Japan Advanced Institute of Science and Technology. He joined JSR Corporation in 2009 and worked in Fine Electronic Materials Research Laboratories. In 2018, he joined JSR Micro, Inc., where he has been engaged in research and development of electronic materials.

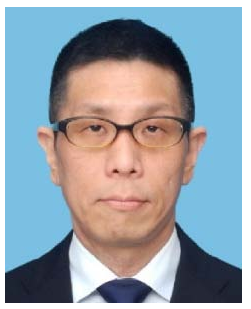

Hiroyuki Ishii received the M.E. degree in chemical engineering from Kyoto University, he joined JSR Corporation in 1998 and has been engaged in the research and development of electronic materials.

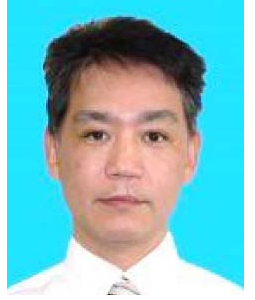

Hitoshi Kato received the M.Sc. degree from Osaka Prefecture University, he joined JSR Corporation in 1997 and has experience in research and development of various materials. From 2014, he has been engaged in material development for 3D packaging technology.

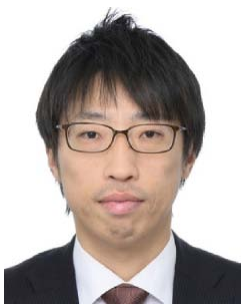

Takashi Mori received the M.E. degree in chemistry from Kyoto Institute of Technology, he joined JSR Corporation in 2008 and belonged to the research and development of electronic materials. He has been engaged in electric materials division since 2016.

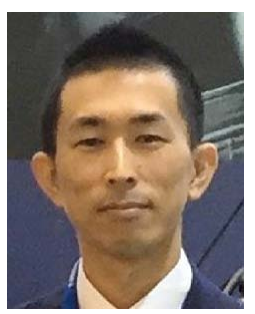

Hiroki Ishikawa received M.S. degree in Department of Chemistry and Biochemistry from the Kyushu University, Japan in 2008. In 2008, he joined JSR Corporation, where he engaged in the research and development of Fine Electronic Materials and Fine Chemical Process.

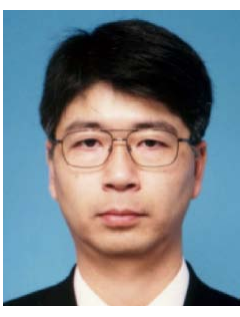

Yooichiroh Maruyama received Ph.D. degree of Eng. at Waseda University in 1994. After Research Associate at Waseda University (1994-1995) and at Osaka City University (1995-1998), he joined JSR in 1998. After the joining, he has been engaged in the research and development of high functional optical resins, and new electronic materials.

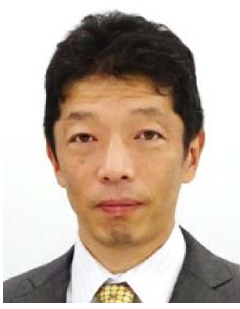

Kenzo Ohkita received Ph.D. degree in Chemistry at Osaka University in 1994. After joining JSR, he has 20 years' experience in research and development of various materials; organometallic polymerization catalyst, functional polymers design, high heat-resistant resins, photoresist for display applications, and materials for printed electronics. From 2014 to 2018, he was responsible as a manager for material development for $3 \mathrm{D}$ packaging technology, especially temporary bonding/debonding (TBDB) materials and photo-definable dielectrics.

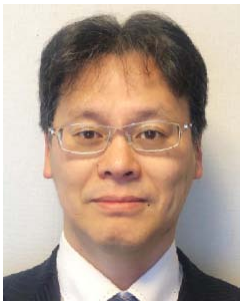

Koichi Hasegawa received Ph.D. degree in Engineering at Osaka Prefecture University in 1999. After joining JSR Corporation, he belongs to R\&D division through his carrier, and involved in electronic and optical materials development. Currently, he is general manager of Advanced Electronic Materials Laboratory in JSR Corporation, dealing photoresists, dielectrics, temporary bonding materials, CMP process consumables and various kind of advanced electronic materials. 